\title{
Ultrassonografia obstétrica e sua relação com a secundarização da experiência da mulher grávida
}

\author{
Obstetric ultrasonography and its relation to the secondarization \\ of pregnant woman experience
}

\author{
Monalisa Nascimento dos Santos Barros' ${ }^{1}$ Claudia Abbês Baêta Neves² \\ ${ }^{1}$ Autora para correspondência. Universidade Estadual do Sudoeste da Bahia. Vitória da Conquista, Bahia, Brasil. \\ ORCID: 0000-0003-3734-3819. barrosmonalisa4@gmail.com \\ 2Universidade Federal Fluminense. Niterói, Rio de Janeiro, Brasil. ORCID: 0000-0002-4615-4377. abbes@luma.ind.br
}

\begin{abstract}
RESUMO | O exame de ultrassonografia obstétrica não faz parte da rotina de pré-natal recomendada pela OMS ou pelo Ministério da Saúde. Entretanto é o exame complementar mais utilizado no pré-natal, mesmo não havendo demonstração de que este procedimento reduza a morbidade e a mortalidade perinatal ou materna. O que produz a busca crescente e a naturalização deste consumo? Que efeitos produz na vivência da mulher gestante? Este trabalho visa discutir como a ultrassonografia obstétrica, em seus usos mercadológicos e procedimentos, produz uma secundarização da experiência da mulher. É um estudo qualitativo que utilizou da observação participante para coleta de dados e utiliza o método de análise do discurso de Pechaux. Foram observados 23 exames ultrassonográficos na cidade de Vitória da Conquista, Bahia, com o objetivo de analisar os discursos presentes durante os exames. Os discursos foram divididos em 6 categorias: A inversão de protagonista a incubadora, Baby Tour e subjetivação dos movimentos, Plateia do espetáculo: produção e consumo de percepções, A venda de produtos ou indução ao tipo de parto, De fetos visíveis aos direitos do nascituro e O corpo que aparece: a desincorporação subjetiva. O modo como a ultrassonografia tem sido usada modifica o lugar-experiência da gestante, transferindo todo o protagonismo para o feto ou para o médico como diretor da cena. O apelo pelo consumo abusivo dos exames facilita sua mercantilização, esfumaça a capacidade de enfrentamento à medicalização e pode resultar na dependência e na alienação.
\end{abstract}

PALAVRAS-CHAVE: Maternidade. Medicalização. Observação participante. Consumo. Análise do discurso.
ABSTRACT | Obstetric ultrasound examination is not part of the prenatal routine recommended by WHO or the Ministry of Health. However, it is the most commonly used prenatal examination, although there is no demonstration that this procedure reduces perinatal morbidity and mortality. or maternal. What produces the growing pursuit and naturalization of this consumption? What effects does it have on the experience of pregnant women? This paper aims to discuss how obstetric ultrasonography, in its marketing uses and procedures, produces a secondization of women's experience. It is a qualitative study that used participant observation for data collection and uses the Pechaux discourse analysis method. Twenty-three ultrasound examinations were observed in the city of Vitória da Conquista, Bahia, in order to analyze the discourses present during the examinations. The discourses were divided into 6 categories: The inversion of protagonist the incubator, Baby Tour and subjectivation of movements, Show audience: production and consumption of perceptions, The sale of products or induction to the type of delivery, From visible fetuses to the rights of the unborn. and The body that appears: the subjective disembodiment. The way ultrasound has been used modifies the pregnant woman's place of experience, transferring all the protagonism to the fetus or doctor as the scene director. The appeal for the abusive consumption of exams facilitates their commercialization, weakens the ability to cope with medicalization and may result in dependence and alienation.

KEYWORDS: Maternity. Medicalization. Participant observation. Consumption. Discourse analysis. 


\section{Introdução}

O exame de ultrassonografia durante a gestação não faz parte da rotina de pré-natal recomendada pela OMS (WORLD HEALTH ORGANIZATION, 2002) ou pelo Ministério da Saúde. Entretanto é o exame complementar mais utilizado no pré-natal pela obstetrícia, mesmo não havendo demonstração de que este procedimento seja efetivo para reduzir a morbidade e a mortalidade perinatal ou materna (BRICKER; NEILSON; DOWSWELL, 2007; JONSSON; BANTA; SCHERSTEN, 2001; REZENDE,2017).

O estudo de Gonçalves et al. (2009) sobre a avaliação da cobertura do exame das mamas e da citologia oncótica cervical entre os exames de pré-natal, comparando-se com o número de ultrassonografias obstétricas realizadas, observou clara priorização da ecografia obstétrica em detrimento do exame físico das gestantes. O autor ressalta que as gestantes muitas vezes pressionam os profissionais de saúde para solicitarem a realização do exame ultrassonográfico por acreditarem ser este um importante instrumento avaliador da saúde fetal, além de proporcionar a possibilidade de saber o sexo da criança. O que produz esta busca cada vez maior por exame ultrassonográfico na gestação?

De acordo com Ortega e Zorzanelli (2010), o extremo uso das técnicas de visualização na medicina vai além de sua eficácia diagnóstica e terapêutica, elas mediam a percepção que construímos sobre o nosso corpo. "A visualização é o meio por excelência de objetivação dos conhecimentos na tradição biomédica ocidental" (p. 27).

A partir da segunda metade do século XX houve uma modificação sensível na forma como as mulheres se relacionam com seu corpo, com a maternidade e com o processo de parturição. As lutas libertárias das minorias e os avanços nas lutas feministas são laminados em meio à dispositivos de saber-poder-subjetivação que, muitas vezes, naturalizam discursos científicos calcados em evidências homogeneizadoras e no fetiche das tecnologias imagéticas. Em seus efeitos de regulamentação e dominação biopolítica nos modos de produção subjetiva, naturalizam a adesão a consolidação de uma lógica assistencial marcada pela intervenção medicalizante do processo de parir. (FOUCAULT, 2006; CLARKE ET AL,2010)

No ordenamento atual da assistência ao parto, dentro desta configuração de dominação em relação ao corpo e a vida, poderíamos descrever a assistência comumente ofertada da seguinte maneira: a gestação é o momento privilegiado no qual a individualidade da decisão é reforçada via o 'direito de escolha', à distância dos aspectos fisiológicos o exercício deste direito recai na escolha por um parto cirúrgico. Associa-se a esta escolha-consumo a promessa de uma intervenção sem dor e com controle de hora, local e dia que condiz com a supremacia da tecnologia e do controle, inclusive para a diminuição da ansiedade e melhor administração do tempo. Neste mesmo processo podemos perceber que há uma supervalorização de exames de imagens, fragmentando o corpo em partes, e sustentando uma espetacularização da gestação. Nesta espetacularização, muitas vezes, relega-se a um segundo plano a relação processual da mulher com seu corpo e com a experiência de parir. Esta relação se torna invisível, a ponto de muitas mulheres duvidarem da sua capacidade e até chegarem a constituir grupos de defesa do direito à escolha da cesárea (CARNEIRO, 2015).

O conceito de subjetividade nos ajuda a pensar, junto com o advento das biotecnologias, o que possibilitou, no contemporâneo, a consolidação desta lógica assistencial. Entendemos a subjetividade como um processo de produção incessante no qual comparecem e participam múltiplos componentes, não sendo "passível de totalização ou de centralização no indivíduo" (GUATTARI; ROLNIK, 2005, p. 31). Esta produção acontece em meio aos encontros que experimentamos com práticas sociais, tecnológicas, humanas, pré-pessoais, pré-verbais. Práticas, estas, produtoras de corpos e efeitos de serialização e/ou invenção nos modos de viver.

Apreendemos o mundo como matéria de subjetivação em meio a dois movimentos: como desenho de uma forma ou como campo de forças. Conhecer o mundo como forma convoca a percepção imediata e 
conhecer o mundo como campo de forças convoca a sensação, à afecção. "Se a percepção do outro traz sua existência formal a subjetividade, existência que se traduz em representações visuais, auditivas, etc., a sensação/afecção traz para a subjetividade a presença viva do outro, presença passível de expressão, mas não de representação" (ROLNIK, 2003, p. 4).

A autora evidencia o paradoxo existente entre esses dois movimentos de apreensão do mundo. Enquanto que no reconhecimento do mundo como campo de forças os blocos de sensações pulsam na subjetividade-corpo quando afetado por novos universos, no reconhecimento do mundo como forma, a subjetividade se reconhece e se orienta no espaço de sua atualidade empírica através das representações. Como o conhecimento do mundo como campo de forças exige uma vivência das sensações e do que lhe afeta, um contato estreito com a experiência subjetiva, essa forma de apreender o mundo vem sendo desacreditada e desestimulada.

Resta o incentivo contemporâneo à forma de conhecimento do mundo como forma, restrita ao mapa da forma vigente com suas figuras, imagens e representações, a cultura somática. Nos exames ultrassonográficos parece haver uma clara experiência de apreensão do mundo pela forma, pela representação do bebê em imagens (Henriques, 2012).

As práticas de assistência ao parto no Brasil sofre uma crescente hospitalização, medicalização e mercantilização (NAKANO, BONAN e TEIXEIRA, 2015). Rodrigues, 2016, conduziu um estudo descritivo de corte transversal, em que se avaliou o número de cesarianas realizadas entre os anos de 2009 e 2011, contrapondo-os com o número de partos naturais, concluiu que o número de partos cesáreos em todos os estados analisados é maior do que o de partos normais. Além disso esse número é crescente e maior em estados com maior IDH. O mais grave é que o procedimento cesáreo vai sendo eleito paulatinamente como principal forma de parto no Brasil.
Entendemos que diversas estratégias se comunam na produção de um corpo assujeitado e conformado ao tipo de assistência médica ofertada, mas o exame ultrassonográfico consegue conjugar o seu grande apelo pelo suposto "encontro" com o feto com uma sutil inversão de lugar da mãe com o feto. O exame ultrassonográfico não é o único dispositivo utilizado para a medicalização da assistência ao parto, ele apenas é um, entre outros! Por ser extremamente sedutor a promessa desse encontro, pouco autores se detém no estudo dos efeitos subjetivos do exame e de que modo ele tem sido realizado.

Qual seria então o lugar do ultrassom no pré-natal? Um exame importante para o acompanhamento do desenvolvimento da gestação ou mais um instrumento de visualização que antecipa a existência do feto como membro da família? A produção crescente de demanda por esta tecnologia contribuiria para a inversão do lugar da mulher de protagonista da gestação para a de expectadora do espetáculo do surgimento do bebê nas esferas sociais? O crescimento no uso das técnicas de visualização, particularmente da ultrassonografia, não seria um elemento preponderante para a positivação da vigilância e da intervenção médica na gravidez e parto? A ultrassonografia cumpre o papel de monitoramento e vigilância no controle da gestação e parto? Que efeitos produz na construção da vivência da mulher gestante?

Neste artigo vamos discutir o exame ultrassonográfico obstétrico, em particular seus usos mercadológicos e procedimentos, por considerá-lo como paradigmático de uma assistência medicalizada à gestação e parto e, também, por ser este uma tecnologia dura, muito utilizada como estratégia potente e efetiva de intervenção tecnocientífica produtora da secundarização da experiência da mulher. 


\section{Metodologia}

É um estudo qualitativo que utilizou da observação participante para coleta de dados (Monico et al., 2017). A observação participante é uma técnica de investigação social em que o observador partilha, na medida em que as circunstâncias permitam, as atividades, as ocasiões, os interesse e os afetos num grupo de pessoas ou de uma comunidade. O objetivo fundamental que subjaz à utilização desta técnica foi a de captação das significações e das experiências subjetivas dos próprios intervenientes no processo de interação social que ocorre durante a execução de exames ultrassonográficos durante a gestação.

Para análise dos dados foi utilizado o método de análise do discurso de Pechaux (1995). O método de análise contemplará a escola francesa de Análise do Discurso, cujos procedimentos, consoante Orlandi (2001) são os seguintes:

a - através de paráfrases e metáforas, tentar-se-á mostrar os prováveis e até "improváveis" efeitos de sentidos do discurso, principalmente à pluralidade, várias possibilidades de leituras que um discurso pode assumir ou não;

b - através da compreensão e do entendimento das relações de inserção e de inter-ação estabelecidas do sujeito com o contexto sócio-histórico-ideológico, a posição social e a ideologia que permeia as relações humanas, influenciando as gestantes a tomarem certas atitudes e não outras.

Para a redação desse trabalho foram feitas observações de exames ultrassonográficos obstétricos em dois serviços, um privado e um público da cidade de Vitória da Conquista, Bahia, com o objetivo de analisar os discursos presentes durante os exames. Foram feitos registros das falas ocorridas no espaço dos exames observados e estes registros foram trabalhados através da análise discurso. Estivemos atentas a que expressões, orientações, sentimentos, indagações eram proferidas, e fazíamos o registro.
Consideraremos o lugar de onde estão falando, as imagens que os interlocutores têm de si, dos outros e ainda o contexto sócio-histórico-ideológico no qual estão inseridos. Entendemos o discurso como fruto da interação entre sujeitos socialmente, historicamente e ideologicamente constituídos. O sujeito não é a fonte, a origem dos sentidos, porque à sua fala atravessam outras falas, outras vozes, enfim; outros dizeres e por que não dizer até outros não-dizeres.

O projeto foi aprovado em 19 de outubro de 2015 pelo Comitê de Ética em Pesquisa da Universidade Federal Fluminense sob o número do CAAE 45483514.6.0000.5243.

Foram acompanhados 23 exames, sendo 5 na clínica privada e 18 no serviço público. Os registros foram realizados a partir das narrativas proferidas dentro do espaço do exame de ultrassonografia obstétrica. Foram observados exames ocorridos entre novembro de 2015 a março de 2016, ressaltando que o nome da clínica, do médico e da gestante foram resguardados. Fazer as observações num serviço público e num privado nos permitiu verificar a existência de diferenças na função do exame, diferenças na positivação da vigilância e da intervenção médica na gravidez e parto, a depender da situação social da parturiente.

Os casos de não aceitação da observação, por parte do profissional médico, foram imediatamente compreendidos e acatados, apesar de não deixarem de provocar um estranhamento. Encontramos resistências em médicos de ambos os serviços. A solicitação era de observação do exame nos quais a gestante teria previamente autorizado à presença da pesquisadora.

A clínica privada será identificada como A. O contato com a clínica foi feito diretamente com o proprietário da mesma. Ele nos encaminhou para a administradora da clínica. Foi apresentado um requerimento de participação como observante nos exames ultrassonográficos realizados na clínica, um resumo do projeto de pesquisa e o Termo de Consentimento Livre Esclarecido, que foi utilizado no contato prévio com as mulheres gestantes. 
Nessa clínica, as ultrassonografias são marcadas na recepção - para designação do dia e do médico que realizará o exame - o horário é definido por ordem de chegada. A clínica é bem arrumada, tem vários espaços para espera. Há várias recepcionistas e várias atendentes, uma para cada médico. Existem diversas salas de exames. Comumente a atendente chama a paciente, leva a uma sala pequena, orienta sobre a roupa, o uso do roupão da clínica e sobre a posição na mesa. $A(0)$ médica(o) entra na sala quando a paciente já está na mesa de exames. Não há muito tempo para apresentações ou para questionamentos quanto ao porquê da solicitação. No caso de ser cliente antiga da clínica estará, na ficha eletrônica da mesma, os resultados de exames anteriores servindo de parâmetro para o novo exame.

A sala é muito pequena, em geral tem a assistente, que vai digitando o exame, a(o) médica(o), a paciente, seu(sua) acompanhante ou acompanhantes. A atendente que a chamou apenas leva a usuária até a sala, a seguir já está localizando a próxima paciente. O exame na clínica privada demora em torno de 15 minutos. Durante todo o exame as informações são passadas à paciente e as diversas partes do bebê vão sendo mostradas no monitor que fica em frente à paciente reproduzindo a imagem do aparelho de ultrassom. Ao mesmo tempo informações para o preenchimento do laudo são passadas à assistente sem que seja identificado claramente a quem está sendo dirigida a mensagem/ informação. Ao terminar o exame, a atendente volta a ser protagonista na cena, orientando a mãe a vestir-se e a esperar na sala de espera pelo resultado. Enquanto isso a(o) médica(o) verifica o exame na tela, solicita alterações à assistente que digitou, autoriza a impressão do laudo, assina e sai da sala já se dirigindo a outra sala onde outra paciente já se encontra esperando pelo exame. $\mathrm{O}(\mathrm{a})$ medico(a) se despede da paciente antes da entrada dela no banheiro para troca de roupa.

As pacientes atendidas, em sua maioria, fazem prénatal em clínicas privadas e realizam em média 6 ultrassons por gestação. Há aquelas em que o ultrassom é um exame mensal durante a gestação e ao final da gestação se torna semanal. Os acompanhantes e pacientes participam ativamente do exame, perguntam, interagem e comentam. Tais comportamentos são vistos como normais e todas as perguntas são respondidas, inclusive com acréscimo de informações. São marcados em torno de 20 exames por turno de trabalho.

O serviço público visitado situa-se dentro de um hospital materno-infantil de alta complexidade da cidade de Vitória da Conquista, Bahia, e aqui será referenciado como $\mathrm{B}$.

O processo para conseguir acesso aos exames foi muito mais complexo. Foi exigido que fizéssemos um requerimento a ser submetido ao Núcleo de Educação da Secretaria Municipal de Saúde acrescido de vários documentos. Foram realizadas algumas reuniões do Núcleo até que o parecer fosse emitido, demorando alguns meses. Depois do parecer da Secretaria, tivemos que fazer todo o procedimento de novo junto ao Hospital e sua comissão de Ética interna. Depois de submetido a Comissão de ética, o coordenador da comissão nos entregou uma carta de apresentação a ser entregue diretamente no Setor de Imagens do Hospital.

Ao dirigir-nos ao Setor de Imagem buscamos a escala dos médicos e explicamos à recepcionista que trabalha no serviço os objetivos da pesquisa, e todo o trâmite referente a aprovação do Comitê de Ética do Hospital e da Prefeitura e da Universidade autorizando o trabalho. Foi uma surpresa descobrir que não seria assim tão simples.

No serviço público as ultrassonografias são marcadas pela central de regulação do município que já direciona o serviço, com dia e turno de atendimento. Não tem horário marcado. A recepção é espaçosa com uma quantidade grande de cadeiras. Só existe uma sala de exame de ultrassonografia. A sala é relativamente grande, em média 12 metros quadrados, possui o aparelho de ultrassom, uma cadeira para a(o) médica(o), uma mesa com um computador, impressora e uma cadeira para a assistente, a maca e em frente um biombo divide a sala ao meio. Do outro lado do biombo estão duas cadeiras, a porta do banheiro e a porta de entrada. 
A atendente chama a paciente enquanto uma já está sendo examinada. A nova paciente entra no banheiro para tirar a roupa e colocar o roupão, enquanto a que está na sala está sendo examinada. Ao sair do banheiro o exame já está terminando e uma deita enquanto a outra vai se vestir. O lençol é trocado a cada duas ou três pacientes. A não ser que haja algum sangramento. Às vezes o lençol é apenas trocado de lado. O exame transcorre tão rapidamente que a ida ao banheiro para trocar de roupa é o tempo de se deitar na maca enquanto a outra está se trocando e o médico verifica o laudo, imprime e assina. Às vezes são marcados até 70 exames por turno de 4 horas. Pelos exames que acompanhamos, a duração média foi de 4 a 5 minutos.

\section{Análise dos dados}

Os discursos foram divididos em 6 categorias: $\mathrm{A}$ inversão de protagonista a incubadora, Baby Tour e subjetivação dos movimentos, Plateia do espetáculo: produção e consumo de percepções, A venda de produtos ou indução ao tipo de parto, De fetos visíveis aos direitos do nascituro e $\mathrm{O}$ corpo que aparece: a desincorporação subjetiva.

\section{A inversão: de protagonista a incubadora}

O que primeiro chamou-nos a atenção foi como a gestante é colocada e fica no lugar de expectadora. Ao mesmo tempo a visão da imagem produz um efeito tão intenso que acaba por dispersar uma leitura das experiências vividas e suas respectivas sensações. O lugar da mulher é de fato modificado. $\mathrm{Na}$ clínica privada ela é chamada a entrar na sala antes do médico e se prepara para ser examinada, ou seja, para que o feto possa ser apresentado na tela. No serviço público, o feto tem ainda mais status, já que as informações são passadas para o médico residente e para a assistente que digita o laudo. Só ao final há informações a serem dadas à gestante.

Os exemplos serão identificados pelo local onde foi feito o exame, com a letra A para a clínica privada e a letra $\mathrm{B}$ para o serviço público, seguido do número do exame observado e a quantidade de semanas da gestação. Quando descrever um diálogo, utilizarei M para a fala do médico, G para a gestante e $\mathrm{P}$ para o parceiro ou acompanhante.

\section{B1. - 28 SEMANAS}

Ela entra na sala, enquanto outra paciente ainda está sendo examinada. O médico pergunta se está indo tudo bem no pré-natal. A paciente anterior se levanta e ela deita. Começa imediatamente a descrever o exame e o bebê. A mulher fica calada, o marido está assistindo. Nenhum dos dois pergunta nada.

O médico está acompanhado de outra médica com quem comenta sobre os parâmetros quase em um cochicho, mostra coisas para ela. Segue passando os parâmetros para a auxiliar que digita o laudo. Pergunta se a paciente já sabe o sexo do bebê. Ela diz que sim. Ele fala: É macho, com certeza! Neste momento mostra as partes do corpo do bebê, diz que está tudo bem e informa o peso do bebê. O casal não fala nada. O exame termina.

Este exame é paradigmático da situação de invisibilidade dos pais, não só da mãe. Apenas as descrições do feto interessavam e, eram repassadas primeiro à médica assistente e depois à assistente que digita o laudo para o médico, em terceiro plano estão a mãe e seu parceiro. Entretanto, a invisibilidade do corpo da gestante está assumida por todos. Retomamos aqui a dimensão de exercício de poder e de dominação social que a dimensão visual da comunicação viabiliza e facilita. A mulher como protagonista da gestação está subsumida, destituída de poder, está no lugar da contemplação mais do que no de vivente desta experiência.

Abaixo um registro da fala de outra gestante:

\section{A5 - 20 SEMANAS}

\section{P. Quero que a gestação seja perfeita, que está sendo} formado direitinho.

O parceiro está preocupado se o corpo da mulher está produzindo um bebê perfeito, saudável. Ela de fato é produtora do protagonista, coadjuvante da cena e do processo. O corpo dela, as transformações nele e sua percepção e sensações não encontram lugar. Estão subjulgados à imagem, à opinião do médico e a mulher não está ali. O silenciamento incomoda à observadora, é um tipo de prática de poder. Há uma invisibilidade inquietante que não é questionada. O médico tem ali toda a delegação de poder de tutela sobre a vida e sobre a determinação de qual vida deve ser valorada. 
Aredoma de silenciamento presente no exame contrasta com a expectativa anterior ao exame. Conversando com as gestantes antes do exame era clara a ansiedade e excitação pelo exame. Muitas descreveram inúmeras dúvidas que tinham e que gostariam de ver contempladas nos diálogos com o médico. Entretanto ao entrarem para o exame o comportamento mudou. Pouco se manifestavam, estavam passivas durante 0 exame com poucos momentos de interação e diálogo. Na maioria das vezes as mulheres se limitaram a ouvir as descrições dadas pelo médico.

Como somente duas ultrassonografias estão prescritas pelo protocolo do SUS para o pré-natal, uma no primeiro e outra no terceiro trimestre de gestação, as mulheres são acometidas de uma grande espera para aguardar o momento do exame. Tanto assim que muitas pagam para poderem ter outras oportunidades de exames em clínicas particulares, mesmo incorrendo em grandes dispêndios financeiros. $O$ exame acaba por não satisfazer ao tão esperado encontro da gestante com o seu feto. Fica no plano da forma, do conhecimento do bebê como forma, restrita ao mapa da forma da imagens e representações, da cultura somática. Não produz encontro, não produz conexão, escapa ao plano da experiência.

O fascínio pela imagem também está presente na disposição de monitores extras para que o exame possa ser acompanhado por todos da sala. Além do monitor do aparelho existem, nos dois casos, monitores em frente à maca e às costas do médico, presos no alto da parede para que qualquer um, de qualquer ponto da sala, possa acompanhar as imagens. Mais uma vez, o corpo que está sendo examinado e manipulado não é o protagonista. O que vale é a imagem do feto.

Uma conversa durante o exame é ilustradora disso:

\section{A4. 33 SEMANAS.}

G. Espero ouvir que está tudo bem! Toda vez que venho aqui choro de emoção. Eu preciso ver para crer, é bom ver os movimentos... Dr. C. é um médico que mostra o desenvolvimento dos órgãos, 2 mãos, 2 pés, ele explica muito. Ele vai além das minhas expectativas. Já fiz sete ultrassonografias, uma por mês!
Outro exemplo do fascínio pela imagem:

\section{A3. 26 SEMANAS}

G. Esse é o terceiro ultrassom que eu faço este mês, fiz dia 6, dia 16 e voltei hoje (26/11). Quero saber o sexo. [...] Se pudesse ficava olhando né? Ficava olhando em casa, né? Tinha até um aparelho desses em casa, né? Igual a Xuxa e Ivete! Olha o coração!

...G. Meu marido fica falando que fico fazendo ultrassom todo dia! Mas eu falei com dr. C e ele me disse que se eu tivesse um aparelho em casa eu poderia ver todo dia!

Nesse caso a promessa do espetáculo é maior do que uma demanda médica, por ser um exame particular não necessita de solicitação médica para a sua execução, pode ser por demanda espontânea da gestante, mesmo que tenha que pagar por isso. A busca por esse 'alívio', que a dissonância entre a percepção e a sensação provoca, motiva novos encontros com a forma de apreensão do mundo pela imagem, no caso, novas ultrassonografias. Podemos, também, pensar as inúmeras realizações do exame de ultrassom como tentativas de se apropriar deste ser que foi objetificado como independente dela. Mas vê-se que não basta. Sete, três num mês... A ocorrência do exame não aplaca a angústia produzida pelo conhecimento do mundo restrito a forma.

A experiência se concentra no campo da percepção formal e não na escuta aos movimentos do corpo sensível (ROLNIK, 2003). O tão aguardado encontro fica no âmbito da representação e neste âmbito nenhum número de ultrassons será suficiente. Este modo de experimentar a gestação produz um investimento no qual a vida está separada de sua potência de criar as próprias e novas condições de existir, pois fica submetida à realidade forjada pela representação visual, organizadas a partir de informações padronizadas que mediam a percepção do corpo e objetificam a relação entre gestante e feto, gestante e médico. Este tipo de apreensão do mundo restrito a forma não favorece a abertura a outros sentidos ou de reconhecimento das sensações ativadas nos encontros. 
Chazan diz que o médico ultrassonografista obstétrico ocupa uma posição mista de educador e entretenedor, onde "simultaneamente ele é roteirista, cameraman, montador, narrador e diretor do show" (2007, p. 159). Há uma exaltação dos aspectos sensório-motores, típica da indústria do entretenimento, como por exemplo, o cinema hollywoodiano. A função de espetáculo está incorporada ao serviço, pois a presença do acompanhante não só é prevista, como esperada. A atendente quando chama a gestante, nos dois serviços, pergunta se está acompanhada. Não é comum a acolhida de forma tão simpática quando o acompanhante se apresenta em outros tipos de exames ou procedimentos médicos. Por exemplo, há a Portaria $n^{\circ} 2.418$, de 2 de dezembro de 2005, do Ministério da Saúde que preconiza a presença do acompanhante, da escolha da gestante, no momento do parto para prestar apoio físico e emocional. Esta portaria é frequentemente descumprida pela falta de entendimento dos profissionais de saúde e gestores da necessidade de viabilizar a presença de tais acompanhantes neste momento. Não há reconhecimento da necessidade de conexão e da experiência vivida neste momento.

Um exemplo, característico de que o espetáculo e o registro dele são mais importantes do que as informações que o exame possa trazer, é o registro descrito a seguir:

\section{B15 - 10 SEMANAS}

Aline já está na maca quando uma amiga entra como acompanhante com uma câmera de celular na mão. Ela diz: Oh, é mesmo! O médico pergunta: Aline, não é? Ela assente. Ele continua: Bem no comecinho da gravidez. A amiga responde pela gestante: É! O médico fica um pouco em silencio e começa a ditar os parâmetros a serem digitados. A amiga faz fotos. Ele fala: pronto, está tudo bem! E ela se levanta, não faz qualquer questionamento, pega o resultado e sai conferindo as fotos na câmara digital. O espetáculo precisa ser registrado e, nele, o ator principal é o feto.

Nos atendimentos abaixo destacamos: a valorização do médico que realizou o primeiro ultrassom e e a expectativa da gestante quanto a correspondência positiva da imagem para 'sentir' o feto:

\section{B12 - 33 SEMANAS}

G. O Sr. quem fez a minha primeira ultrassom! (exclama como se tivesse sido um momento muito especial)

M. Fui eu quem fiz?

\section{A5 - 20 semanas}

G. Ai, Ai, tomara que esteja com as pernas abertas! Se fosse por mim, faria uma ultrassom a cada 15 dias. Mês passado, fiz 2 vezes, para ver se estava perfeitinho, como ainda eu não sinto, então ver me dá segurança! o último ultrassom daqui, eu não gostei, não. A médica era muito confusa e a imagem estava horrível!

A avaliação positiva direciona-se à qualidade da imagem e as informações obtidas pela gestante não apresentam nenhuma relação aparente com a eficácia das medidas ou dos parâmetros solicitados pelo médico que acompanha a gestação e que, teoricamente, justificariam a solicitação do exame frente a insegurança da gestante. $O$ bebê é a celebridade com a garantia de seus poucos minutos de fama, mesmo que restrita ao ambiente doméstico. A sensação de insegurança diz de uma desconexão entre a experiência subjetiva (corpo-afecção) e a imagem como possibilitadora de reconhecimento perceptivo do mundo formal. O que produziria esta sensação de insegurança ao não visualizar a existência do feto pelo monitor?

Não poderíamos pensar nesta narrativa a produção de uma desconexão com a experiência subjetiva que leva a busca de mais ultrassonografias nas quais a imagem permite a experiência da percepção do mundo formal? A desvinculação da experiência subjetiva de estar grávida, do sentir-se grávida, da sensação da presença viva do outro é substituída e ou desvalorizada, muitas vezes, por uma percepção, por uma imagem objetiva e formal da existência do feto em seu corpo. É como se a imagem oferecesse um substituto à sensação! O que gera o desejo por mais consumo de exames de ultrassom. 
Para Illich, a prática de procedimentos rotineiros de diagnóstico precoce "reforça a convicção das pessoas de que são máquinas cuja durabilidade depende da frequência das visitas à oficina de manutenção, e elas são obrigadas a pagar para que a instituição médica possa fazer seus estudos de mercado e desenvolver sua atividade comercial" (1975, p. 50).

As mulheres adoram os exames ultrassonográficos e passam dias à espera deste 'encontro' com o bebê. Apesar de o feto estar dentro dela, a mediação da tecnologia na produção da imagem parece transformar esse momento em "mais" real do que as sensações diárias desenvolvidas entre a gestante e o feto. Apesar da ansiedade e motivação para o exame, foi possível, também, perceber que o exame não basta, que, ao findar aquele exame, já há o interesse pelo próximo exame/encontro e que o modo como estes exames são realizados, com baixo grau de troca entre gestante e médico, não aplaca a insegurança frente à própria gestação e ao parto. "A mulher perde seu lugar de sujeito, de protagonista e se torna um objeto da medicina "(OLIVEIRA, 2017).

O papel da visualização na construção social e cultural da maternidade se tornou parte da vida moderna e as imagens médicas lentamente foram assumindo uma relação autoevidente com o feto, como se antecipassem a existência daquele novo membro da família. Rezende (2017) estudando acerca das histórias de parto e a ultrassonografia como marco narrativo afirma que a ultrassonografia obstétrica contribui para a normatização da gravidez com "o monitoramento constante de si a ser mantido pela gestante e por seu obstetra, como exemplo do regime disciplinar dos sujeitos discutido por Foucault (1997), no qual os corpos são tratados de forma a maximizar sua utilidade e eficiência ao mesmo tempo em que são individualizados." Desaparece deste modo a mulher e evidenciando apenas a portadora do feto, a incubadora viva.

\section{Baby Tour e subjetivação dos movimentos}

Há um roteiro na execução dos exames que inclui um passeio pelo corpo do feto com as imagens sendo descritas por partes do corpo. Em todos os exames observados ocorreu essa descrição. Durante a descrição é comum ver o médico utilizando palavras no diminutivo, adjetivando alguns movimentos ou atribuindo qualidades estéticas ao feto. “Reforçando a hipótese de que a ultrassonografia obstétrica não apenas antecipa a existência social do feto em termos da rede de relações sociais, como constrói a 'realidade' do próprio concepto para os futuros pais" (CHAZAN, 2005, p. 265).

Vejam os registros abaixo:

A1 - 12 SEMANAS.

M. Do bumbum até a cabecinha mede $7,4 \mathrm{~cm}$.

G. Já é um cidadão, já pode pagar as contas, já pode trabalhar!

M. Coraçãozinho, ó? Coluna. Tá vendo? por aqui é melhor. 145 batimentos. Do bumbum até a cabecinha está com $8,3 \mathrm{~cm}$. Fêmur... Já é feto, não é mais embrião. Já aparece o estômago cheio de líquido, isso é bom. Significa que o bebê está engolindo. Tem um pouquinho mais de tempo do que vcs estão pensando. É a sua primeira ultrassom? Só falta aqui a gente ver a cabecinha, a coluna, a mãozinha, o bracinho...

Aqui, o diminutivo promove certa identificação do médico com o feto apresentado como um bebê ou melhor descrito pela gestante: como um cidadão! Ela pode até não existir no cenário, mas o futuro bebê ganha status e cidadania.

No exame descrito abaixo, a qualificação dos movimentos como uma cambalhota ou dizer que os bebês adoram pegar no saco desde a gestação, configuram socialmente o concepto como um bebê. 
M. Veja o rostinho, os olhos, a boca, está chupando a

mão!

M. Craniana 6,4. Dopi 5,2. Aqui a barriguinha. 0 estomago. $O$ bebê engole liquido, faz xixi, torna a engolir. Abdominal 14,2 Por aqui está dando 19s3d. Olha o rostinho, a mãozinha na cabeça. Tá quase dando uma cambalhota. As perninhas. Olha lá o pintinho bem nítido. O bebê pegando no saco, eles adoram pegar aí desde a barriga. O pezinho, cinco dedos. Não sei por que mas os dedos são bem importantes para vcs! Só vou calcular o peso. Aqui está dando mais tempo, por aqui está dando 19s 3d. Quem

é a sua médica?

G. Dra. L.

M. Olha a mão na cabeça, ó? Olha o nariz, olhos, boca... As pernas para cima, tá vendo ó?

G. Oh, meu Deus!... (visivelmente emocionada).

Outro exemplo de subjetivação dos movimentos fetais está presente na qualificação, por parte da mãe, de que ao colocar a mão na boca, significa que o feto está com fome. Ela fala isso em voz alta, mas o médico não contesta aceitando essa forma de qualificação da imagem. Podemos inferir que há uma política de subjetivação alocada num modelo identitário e representacional, que busca uma homogeneização de sentidos. Todos os movimentos do feto adquirem status qualificados de subjetivação, de antecipação da existência.

B12 - 33 semanas

M. Ve quer perguntar alguma coisa?

G. Aqui, vai ser bem cabeludinho, né?

M. Vc está vendo, né?

G. É uma moça?

M. É uma menininha, mulher!

G. Maria Clara!
G. Tá com fome! Ô, gente! Tá com fome!

E já se levanta. Sai feliz!

A situação de espetáculo está presente, inclusive no humor com que são descritas algumas imagens. O médico participa ativamente da construção do show. Vejam o registro abaixo:

\section{B7. - 29 SEMANAS}

G. É homem, Dr.?

M. Te falo agora. É, com certeza! Pode comprar a camisa do flamengo para ele.

G.O pai é vascaíno.

M. Pelo ultrassom, ele torce pelo flamengo. É homem

mesmo!

A subjetivação e psicologização dos fetos têm sido tão comuns que mesmo o médico que faz a ultrassom é tomado por esse modo de subjetivação da gestação e do feto. Após um turno de acompanhamento de seu trabalho o médico vira-se para a observadora e pergunta: "Posso lhe fazer uma pergunta pessoal?". Respondo: “Diga!". Ele então continua: "Vc acha que a minha filha sabe que eu desejei que ela fosse um homem?". Eu perguntei: "Por que?". Ele: “Minha mulher está grávida e quando eu fui fazer a ultrassom e não vi o pênis... Nunca procurei tanto por um pênis!... Fico pensando nisso e me perguntando se ela sentirá que eu a rejeitei, no início. Agora, não!". Pergunto: "Ela tem que idade?". Ele: "Vai nascer daqui a três meses!”.

De acordo com Chazan e Faro(2016), ao estudarem a biomedicalização e a estratificação nos usos do ultrassom obstétrico no Rio de Janeiro, reportam como a interação com as imagens, fundindo a visualidade 
com suas sensações corporais, constituíam um determinado tipo de corpo grávido. "A seus fetos eram atribuídas intencionalidades e idiossincrasias, tornando-os sujeitos subjetivados e nomeados desde antes do nascimento"(CHAZAN E FARO, 2016, p 73). A subjetivação antecipada de um futuro bebê produz a materialidade esperada de um filho ainda por nascer.

\section{Plateia do espetáculo: produção e consumo de percepções}

Para todo espetáculo há uma plateia. No caso dos exames de ultrassonografias obstétricas as plateias se formam com a presença dos acompanhantes na cena do exame, mas, também, com a produção de vídeos e fotografias das imagens do monitor, assim como registros de fotos do momento do exame, muitas vezes com o médico fazendo parte das cenas e das poses. Dos 21 exames observados, houve uma variedade grande de acompanhantes: avós, pais, fiIhos, amigas! Todos os laudos vão acompanhados de fotos e fotos artisticamente produzidas, em geral do sexo, do rosto ou de alguma imagem mais significativa surgida no exame: o feto fazendo movimentos com as mãos, interpretadas como tchau, sugando o dedo, um perfil que mostre bem um nariz, uma mão aberta mostrando ter cinco dedos...

Nas observações realizadas, foi comum as gestantes chegarem com um pendrive, ou com uma câmera. Mas, o mais inusitado foram as postagens no facebook ou no twitter em tempo real!

\section{A2 - 19 SEMANAS}

M. Certeza! A cabecinha... Já está de cabeça para baixo. Dorso para a direita. Placenta posterior, homogênea grau zero. Aqui o coraçãozinho, ó? Frequência cardíaca de 132 batimentos. Ai a cabecinha, ó? Biparietal, 4,5.

\section{P. Já postei no Face.}

M. Vc é rápida, heim?

\section{P. Já mandei a mensagem.}

P. Perfeito, né? Todos os dedos, eu já contei!

M. Não sei por que, mas os dedos são bem importantes para vcs! Vou fazer uma foto do pintinho para ve ter certeza!
Pouco a pouco o processo de assistência ao pré-natal vai se dirigindo a um posicionamento passivo e dependente da mulher que resultará em uma desaproriação do seu próprio corpo e na desconfiança acerca da possibilidade de gestar e de ela própria conduzir o seu parto.

Bruno (2013: 53) afirma que a disciplina e o espetáculo são dois vetores de visibilidade "com implicações fundamentais para a subjetividade". No estudo de Karhawi, 2015, sobre fenômeno contemporâneo das selfies, conclui que o sujeito das selfies construiu-se sob um regime de visibilidade midiática espetacular em que ser visto é existir. A vida passa a ser mediada por imagens, as selfies seriam um espaço em que o olhar do outro legitima sua existência. Sendo assim, a ultrassonografia, suas imagens e fotos legitimam a existência desse bebê, a visibilidade são as marcas de nosso tempo, de acordo com Karhawi, marcas de um processo de subjetivação do sujeito, da construção de sua singularidade que quanto mais vista mais garante sua existência. Talvez essa marca de visibilidade total com as redes sociais possam contribuir ainda mais para esse lugar tão paradigmático para este exame. Aqui especialmente a existência de alguém que ainda está literalmente por vir.

\section{A venda de produtos ou indução ao tipo de parto}

Com a produção do feto como indivíduo que consome, a venda de outros produtos é apenas uma consequência. Tudo promovido por uma sedução constante, mantida pelo prazer em ver, em antecipar a existência do futuro bebê.

\section{A3 - 26 SEMANAS}

\section{G. Aqui faz aquela colorida?}

M. Vc está falando da 3D, sim, faz! Tem que ter um pedido específico para fazer essa. Fale com o seu médico!

A ultrassonografia passou a ser um produto de consumo altamente demandado no processo da gestação. Com satisfação imediata e seu uso, muitas vezes desvinculado das singularidades do processo, em prol do gozo momentâneo da imagem, o que se reforça neste processo é uma conexão frágil e superficial com o plano da experiência da gravidez. Assim, outros exames ou tipos de exames vão sendo buscados até o final da gestação como forma de acesso a 
este gozo imediato. Este se constitui como mais um campo fértil para a emergência de novos produtos a serem consumidos.

$\mathrm{Na}$ assistência ao parto, os serviços privados tratam seus usuários como consumidores: ali eles são clientes. Os clientes são frequentemente divididos em públicos-alvo, o que torna possível combinar produtos para os potenciais compradores e divulgar isto adequadamente. Vendem-se ultrassonografias simples, colorida, 3D, anestesia, ultrassom morfológica, fotógrafos e cineastas do próprio hospital, diversos tipos de anestesias que podem ser combinadas antes, serviços de doulas, salões de beleza dentro de hospitais, quarto ou ambulatório, serviços de buffet, produção de lembranças personalizadas com fotos do bebê ou do parto, transmissão on line, assistência com o mesmo médico do pré-natal. Para o mercado, o que interessa é a criação de demandas de consumo, produzidas, muitas vezes, a partir de argumentos envoltos em racionalidades ditas científicas e/ou através da sedução, da venda de produtos que 'facilitam' a vida da mãe, do gozo, da felicidade, de uma saúde integral, sem riscos. O papel do consumidor assume cada vez mais relevância até ao ponto de o consumidor ser, ele próprio, um produto à venda.

No campo da saúde pública, há diferenças, mas também se configura um privilégio à ótica da 'escolha' para seus usuários. Diferente da ótica de escolha individual na versão mercado as ofertas de produtos a serem consumidos têm o protagonismo dos profissionais de saúde que devem orientar escolhas adequadas e saudáveis baseadas em estudos epidemiológicos. Contudo, o que é bom para a população, nem sempre é igualmente bom para seus membros individualmente. Em uma lógica de cuidado a diferenciação e a especificação são cruciais na garantia e no respeito às singularidades presentes em cada caso.

Em contrapartida, a virulência dos dispositivos de exclusão socioeconômica está aumentando e poucas muIheres possuem condições econômicas para acessar e ou consumir todos os serviços disponíveis. Contudo, indagamos: o que querem e produzem como valor estas ofertas de acesso/consumo? trata-se de acessar? que campos de necessidades se produzem?
"Vivemos sob o constructo de uma cultura patriarcal, cultura que influenciou várias narrativas discursivas, entre elas, o discurso médico que tem a atenção voltada para o controle do corpo da mulher. Além da cultura patriarcal, o sistema é capitalista e a sociedade é consumista, as relações são mercadológicas e o parto, portanto, faz parte dessas relações de mercado, não seria absurdo dizer que o parto tornou-se uma indústria" (OLIVEIRA, 2017, P.4).

Nesta lógica da escolha individual, seja na versão do mercado ou mesmo na versão 'adequada e saudável' dos experts, o que vira mercadoria junto com os bens materiais é a própria experiência vivida!

\section{De fetos visíveis aos direitos do nascituro}

A individuação produzida ao antecipar a existência social do feto através da visualização bem antes do nascimento, destaca-o da gestação. Em poucos momentos, durante a observação dos exames, houve interesse por parte dos profissionais em fazer perguntas sobre a gestante ou de como estava experienciando a gestação. O bebê era sempre o protagonista das atenções, o que produz um deslocamento em que qualquer esforço requerido à gestante será sempre bem acatado, desde que seja em benefício do bebê. "O feto singularizado e medicalizado é tornado público e pode ser inserido socialmente como indivíduo" (CHAZAN, 2005, p. 300-301).

A antecipação social da existência do bebê ganha força e se expande em outros campos, por exemplo, no campo jurídico. No Brasil já há diversos projetos de lei que garantem os direitos do nascituro e, entre outros, destaca-se o Estatuto do Nascituro que reconhece o direito à vida desde o momento da concepção (LAPA,2013).

O Estatuto elenca todos os direitos inerentes à criança por nascer, já afirmados pelo direito internacional, tornando integral a proteção ao nascituro, sobretudo no que se refere aos direitos de personalidade. Ao estado ou a particulares é vedado causar dano ao nascituro em razão de ato cometido por qualquer de seus genitores. Isto inverte a hierarquia mãe-feto, além de atribuir autonomia e posicionar o feto como mais importante, como pessoa e sujeito de direitos antes mesmo de nascer, ficando a mulher como acessório, 
como coadjuvante nesta produção onde o feto é o centro, mas as decisões são tomadas pelo médico detentor da tecnologia e do poder de intervenção e pela justiça.

Neste ano (2019), completa 12 anos o trâmite, no legislativo brasileiro, do Estatuto do Nascituro. O projeto causa polêmica ao instituir direitos civis e penais a embriões, dentro ou fora da barriga da mãe, uma vez que considera como ser humano células fecundadas por processo natural ou in vitro, mesmo antes da transferência pra o útero da mulher. O projeto de lei em si é uma aberração, lotado de contradições, a começar pelo fato de outorgar a um ser que nem mesmo pode ser considerado pessoa (pelo simples fato de não ter nascido) a liberdade de reclamar direitos jurídicos e proteção do Estado (LAPA, 2013).

Assegurar ao nascituro a "absoluta prioridade" no direito à vida significa retirar da gestante o direito de abrir mão da gravidez, mesmo quando esta a submeta a risco de morte, afinal, a prioridade à vida seria do feto e não da mãe. O Estatuto do Nascituro vai na contramão de toda a discussão que tem sido feita até hoje, em nosso país, acerca da necessidade de se ampliar o direito ao aborto. O aborto no Brasil é uma questão de saúde pública. Estima-se em mais de um milhão o número de abortos clandestinos realizados todos os anos, dos quais 200 mil resultam em internação hospitalar (BRASIL, 2011).

O tema aborto é complexo e permeado de conflitos: admitir a maternidade como uma opção e não uma obrigação é ainda imenso tabu e o controle social da função reprodutiva das mulheres é um dos pontos centrais de disputa em nossa sociedade. Neste contexto, grupos conservadores, sob o aparente interesse da proteção à vida, combatem qualquer medida que favoreça a escolha da mulher sobre sua reprodução, opondo-se, inclusive, a direitos já conquistados.

Ser contra o Estatuto do Nascituro não é ser contra a vida. É observar que o que está em jogo na discussão do tema aborto é a vida de um ser humano constituído e sujeito de direitos, a mulher. Nascituros não são pessoas, são vidas em potencial, e o direito à proteção jurídica da vida desde a concepção não existe em nosso ordenamento jurídico constitucional, nem nos tratados internacionais que o Brasil ratificou. Então, pode-se dizer que "nascituro" é criação para dar personalidade jurídica às convicções morais de homens que desejam controlar a reprodução das mulheres pela lei penal (LAPA, 2013, p. 2).

A secundarização da experiência da mulher na gestação é exercida não apenas pelo consumo das tecnologias duras, tais como os exames ultrassonográficos, mas também se ancora em práticas patriarcais presentes na assistência obstétrica, no legislativo e no judiciário brasileiros. Práticas de violação de direitos e de invisibilização da mulher! Práticas de violência de gênero!

\section{0 corpo que aparece: a desincorporação subjetiva}

Como vimos, chama a atenção o silêncio dos acompanhantes e das gestantes durante o exame. Para a observadora, é reservada uma cadeira junto à porta e não há qualquer expectativa de que a observadora fale ou pergunte alguma coisa. Aliás, há a expectativa de que ela esteja muda! É interessante que a observadora tenha atendido a esta expectativa. Ela ficou muda! A dinâmica desenvolvida no atendimento, como uma linha de montagem, as falas do médico dirigidas, principalmente, para a secretária que digitava o exame, as informações sucintas dirigidas à mulher, o impacto do silêncio das mulheres frente ao desenvolvimento do exame... tudo junto produziu na pesquisadora o mesmo silenciamento!

Ao analisar os registros foi possível verificar: a fragmentação e descorporificação da gestação em que o produto (feto) é o protagonista; o consumo de novas ultrassons é incentivado e a determinação do sexo é mais valorizada do que qualquer outro dado; as atividades do feto são subjetivadas; a produção e o consumo de imagens são incentivados e o espetáculo é o motor do exame. Nas raras ocasiões em que o exame identifica uma anormalidade é que a cena se modifica e de espaço de espetáculo se transforma em um espaço médico. 
A retirada da mulher da cena, o protagonismo do feto alçado à condição de cidadão, o papel do médico como diretor da cena e portador do discurso oficial da saúde seriam respostas mais plausíveis para o aumento da ansiedade traduzida na necessidade cada vez maior de captura destas imagens e da realização cada vez mais constante dos exames.

Illich vai chamar a demanda incessante por exames médicos de etiquetagem iatrogênica das diferentes idades da vida humana que se torna parte integrante da cultura quando "o leigo aceita como coisa 'natural' e banal o fato de que as pessoas têm necessidades de cuidados médicos de rotina simplesmente porque estão em gestação, são recém-nascidas, crianças, estão no climatério, ou porque estão velhas" (1975, p. 43). A naturalização desta demanda torna cada vez mais difícil a contestação ou problematização acerca da lógica do consumo na saúde. O silenciamento da mulher no exame revela uma condição advinda da medicalização. "É o ritual da medicina, celebrado por um mago preventivo, que priva os homens da posse do presente" (ILLICH, 1975, p. 56).

Orlandi (2007) fala sobre os silenciamentos, como uma política do sentido, existe uma historicidade no que pode ser dito, ou no "poder dizer". A política do silêncio produz um recorte entre o que se diz e o que não se diz. O que podemos ver na política do silêncio, é o silêncio constitutivo que mostra o que pode ser dito, o que dizer para não permitir o que foi silenciado de ser dito.

Este silenciamento, como vimos, é construído desde a assistência pré-natal e, ao que parece, os exames de ultrassonografias acabam sendo parte do mecanismo que produz silenciamento e afastamento da experiência no corpo, produzindo constrangimentos na potência de agir. Claro que este não é o único efeito nem o propósito do exame. Por ser um exame extremamente sedutor, com todo espetáculo produzido, em uma sociedade extremamente visual e midiática e sendo altamente demandada pelas muIheres, parceiros e família, acaba sendo um dispositivo bastante sutil na promoção desta inversão no protagonismo da mulher frente à gestação.
Podemos perceber, no caso do uso crescente dos exames ultrassonográficos, que o fascínio pela imagem e tudo que ela traz em seu entorno de espetacularização contribui para a manutenção de uma relação desigual e hierárquica entre gestantes e profissionais de saúde, ao mesmo tempo em que vende a promessa da construção de um vínculo maior entre gestante e feto.

Nos protocolos brasileiros de assistência à gestação, o exame ultrassonográfico permite a avaliação do número de embriões ou fetos, do posicionamento do feto e da placenta no útero, dos batimentos cardíacos fetais, de medidas anatômicas que permitam fazer uma estimativa da idade gestacional e do peso fetal, identificando problemas no crescimento e, eventualmente, determinando a época adequada para a intervenção cesariana. [...] Conforme assinala Taylor (1998), o valor estritamente médico do ultra-som é duplo: pode ser utilizado sozinho como método diagnóstico no pré-natal, e em conjunto com outras técnicas e testes para a tomada de decisões acerca do manejo da gravidez (CHAZAN, 2005, p. 152-153).

Mas a autora destaca, ainda, os benefícios psicológicos para a gestante dos exames de ultrassonografia. Para Anthony Reading (1982), um dos efeitos psicológicos imediatos da ultrassom é a acentuação da consciência da existência do feto, o que ajudaria na formação do vínculo mãe-bebê e mãe-médico, facilitando, inclusive, que a mãe adote os comportamentos recomendados pelos médicos, tais como parar de fumar ou beber, mais facilmente.

\section{Ainda para Chazan:}

[...] a teoria dos 'benefícios psicológicos' vincula-se de modo estreito à disciplinarização e à medicalização dos comportamentos das gestantes, exercendo um papel potencialmente normativo sobre elas no mesmo processo em que é reforçada a subjetivação $d a$ gravidez e da gestante (2005, p. 154).

Carneiro, 2015, discutindo acerca dos grupo de parto humanizado e das mulheres que os frequentam propõe a categoria experiência para sustentar a tese de que, para além da rejeição a um uso abusivo de 
tecnologia e de cirurgia no parto - em função das iatrogenias ou por solapar o protagonismo feminino as mulheres buscam resistir ao empobrecimento de sua experiência reprodutiva, resultante de uma assistência rotinizada, padronizada e despersonalizada.

A política de subjetivação hegemônica não é a que favorece a processualidade da vida, pois, esta depende da força de invenção que decompõe mundos e compõe outros, garantindo a vida em sua continuidade e expansão. Diferente disto, favorece a dissociação de sensações, havendo uma separação do corpo e de suas afecções, do que ele pode como multiplicidade/variação.

\section{Considerações Finais}

O exame ultrassonográfico funcionaria como mecanismo coadjuvante na manutenção do ordenamento atual na assistência ao parto. Aliado importante na manutenção da assistência medicalizada e centrada no médico. Não queremos aqui demonizar ou mesmo contraindicar o uso da tecnologia da ultrassonografia, mas alertar que o seu uso tem sido um dispositivo, entre outros, utilizado para a inversão do protagonismo da mulher para o feto frente à sua gestação. Reconhecemos o grande apelo que este exame produz dentro do imaginário feminino e familiar em torno do "encontro" com o futuro bebê. Talvez o que se coloque como desafio seja que modos de operar poderiam ser desenvolvidos que permitissem a potencialização deste exame como experiência de cuidado vívida?

O cuidado seria, prioritariamente, "fazer com que a vida se torne potente, forte, criativa, inventiva, ativa, que goze realmente, produza o gozo alegre como consumo de intensidades livres sem as quais não haveria transmutação do desejo nem saúde em ato?" (FUGANTI, 2009, p. 670). Ao contrário disto, descrevemos um tipo de assistência que produz o silenciamento da mulher, a subjetivação do feto, que reforça diferenças de gênero e dispara novos desejos de consumo, incita à subjulgação fazendo subsumir a fala da mulher, a sua segurança enquanto quem gesta e pare uma criança, viola direitos sexuais e reprodutivos.
Estas práticas de poder produtoras de dependência, reforçadoras de normalização, medicalização e mercantilização da experiência da gestação, com a promoção de uma inversão onde a mulher deixa de ser protagonista, autora, produtora para ser paciente de um médico e incubadora de um futuro cidadão, tudo isto reforça a iatrogenia social e estrutural, como diz Illich (1975), e reassegura as diferenças de gênero.

Ao esvaziar a experiência de gestação das sensações e vinculá-la apenas à percepção da forma-imagem não se estaria produzindo inseguranças? Não seria este o momento em que a figura do médico recebe todo um investimento reificado de grande salvador? O desejado e esperado encontro entre gestante e feto subjetivado, promete coisas que não cumpre, movimentando a demanda por outros e outros exames, servindo mais na produção de um corpo que não importa, um corpo sem fala.

Não se trata de desvalorizar, aqui, o valor das percepções e sensações advindas do exame. Elas são desejadas, buscadas e, inclusive, pagas pelas muIheres para obtê-las. Contudo, não podemos deixar de ressaltar como a supervalorização deste dispositivo no acompanhamento pré-natal, mediado pela imagem, tem contribuído para reforçar o papel do médico como central nas decisões e definir uma biopolítica normalizadora dos usos dos corpos.

As observações realizadas não permitiram identificar uma rede de cuidado em conexão com as experiências da mulher. Em nenhum momento foi verificada alguma indicação de interação com outros elementos de cuidado presentes no contexto: por exemplo, alguma pergunta acerca do serviço que a mulher tem utilizado para acompanhar a gestação, suas dúvidas e/ou apreensões. Talvez, esta intensa 'vontade' de ultrassom tenha sido o que restou à mulher na construção desta assistência tão monitorada e medicalizada. Mais uma violência de gênero sutil, bem aceita, mas com claros resultados sobre a inversão simbólica quanto ao lugar da mulher na cena do parto. 
Esta inversão reforça, mais uma vez, a dicotomia entre maternidade e feminilidade, pois, ao passo que os corpos femininos desfilam sensualidade e erotismo nas publicidades e revistas brasileiras, com uma extensa exposição da mulher, o corpo grávido e escondido pela superexposição do bebê é silenciado e invisibilizado durante o pré-natal.

As tecnologias de visualização podem produzir a desincorporação subjetiva e a virtualização e objetivação da corporeidade. De acordo com Ortega (2008), as tecnologias de visualização são tentativas de transformar o estranho em familiar, de tornar previsível, disponível, acessível uma dimensão da corporeidade que é, por natureza, recessiva e ausente, que se recusa e recua da apreensão direta. É uma tentativa de fugir da ansiedade básica de algo que não posso controlar, que escapa à minha apreensão e, no entanto, me habita. É uma forma de escapar do encontro com novos blocos de sensações que, esvaziados de vitalidade, perdem a potência.

A secundarização da experiência da mulher e a inversão de protagonista a coadjuvante de que falamos neste trabalho modifica o lugar-experiência da gestante, transferindo todo o protagonismo nesta relação para o feto ou para o médico como diretor da cena. "Um dos resultados do discurso médico é a submissão da mulher. Nesse sentido, não faz muita diferença que ocorra uma cesárea ou um parto normal, o médico não assiste, ele intervém. O protagonismo da mulher foi retirado" (OLIVEIRA,2017). $\mathrm{O}$ apelo pelo consumo abusivo dos exames facilita sua mercantilização, esfumaça a capacidade de enfrentamento à medicalização e pode resultar na dependência e na alienação.

Ressaltamos que o presente estudo tem um escopo pequeno e com limitações bastante expressivas quanto a possibilidade de generalização de seus achados, por isso entendemos que mais estudos devam ser desenvolvidos para aprofundar essa relação entre o consumo da imagem, formação de um desejo continuo para mais exames verso protagonismo feminino na gestação e como isso impacta na experiência da mulher.

\section{Contribuiç̧̃es das autoras}

Barros MNS é a autora principal. O artigo é parte da sua tese "Reconfigurando um Modo de Ver o Parto", defendida em 15 de dezembro de 2015, na Universidade Federal Fluminense. Neves CEA orientou a tese e participou ativamente na escrita do artigo e nas discussões finais.

\section{Conflitos de interesses}

Nenhum conflito financeiro, legal ou político envolvendo terceiros (governo, empresas e fundações privadas, etc.) foi declarado para nenhum aspecto do trabalho submetido (incluindo mas não limitando-se a subvenções e financiamentos, participação em conselho consultivo, desenho de estudo, preparação de manuscrito, análise estatística, etc.).

\section{Referências}

Brasil. (2011) Ministério da Saúde. Secretaria de Atenção à Saúde. Departamento de Ações Programáticas Estratégicas. Atenção humanizada ao abortamento: norma técnica / Ministério da Saúde, Secretaria de Atenção à Saúde, Área Técnica de Saúde da Mulher. 2. ed. Brasília: Ministério da Saúde.

Bricker, L., Neilson, J. P., \& Dowswell, T. (2008) Routine ultrasound in late pregnancy (after 24 weeks gestation). Cochrane Database Syst Rev, (6):CD001451. Recuperado de https://www.ncbi.nlm.nih.gov/pubmed/26121659. doi: 10.1002/14651858.CD001451.pub4

Carneiro, R. (2015). Cenas de Parto e Políticas de Corpo. Rio de Janeiro: Editora Fiocruz.

Castel, R. (1991). From dangeroussness to risk. In G. Burchell, C. Gordon, \& P. Miller (Ed.). The Foucault effect: studies in governamentality. Londres: Harverster-Wheatsheaf. p. 281-298.

Chazan, L.K. \& Faro, L.F.T. (2016). "Exame bento" ou "foto do bebê"? Biomedicalização e estratificação nos usos do ultrassom obstétrico no Rio de Janeiro. História, Ciências, Saúde - Manguinhos, 23(1), 57-77. Recuperado de http://www.scielo.br/pdf/hcsm/v23n1/01045970-hcsm-23-1-0057.pdf. doi: 10.1590/S0104$\underline{59702016000100005}$ 
Chazan, L. K. (2005). "Meio quilo de gente!" produção do prazer de ver e construção da pessoa fetal mediada pela ultrasonografia: um estudo etnográfico em clínicas de imagem na cidade do Rio de Janeiro (Tese de doutorado). Instituto de Medicina Social, Universidade do Estado do Rio de Janeiro, Rio de Janeiro, RJ, Brasil.

Chazan, L. K. (2007) "Meio Quilo de Gente": um estudo antropológico sobre ultra-som obstétrico. Caderno de Saúde Pública, 24(4),941-943. Recuperado de http:// www.scielo.br/scielo.php?script=sci_arttext\&pid=S0102311X2008000400026. doi: 10.1590/50102$\underline{311 \times 2008000400026}$

Clarke, A. E., Mamo, L., Fosket, J. R., Jishman, J. R., \& Shim, J. K. (2010). Biomedicalization: Technoscience, Health and IIIness in the US. Durham: Duke University Press.

Debord, G. (1997). A sociedade do espetáculo. Rio de Janeiro: Contraponto.

Dias, J. F. (2007). O renascimento do parto: discurso e identidade (Dissertação de doutorado). Universidade de Brasília, Brasília, DF, Brasil. Recuperado de https://repositorio.unb. br/handle/10482/1449

Esequiel, V. C. (2006). O marketing da responsabilidade social e a transformação das "questões Sociais" em Espetáculo. In C. N. P. Coelho, \& V. J. Castro (Org.). Comunicação e sociedade do espetáculo. São Paulo: Paulus.

Foucault, M. (2006). História da sexualidade l: a vontade de saber. Rio de Janeiro: Edições Graal.

Fuganti, L. (2009). Biopolítica e produção de saúde: um outro humanismo? Interface Comunicação Saude Educação, 13(supl. 1), 667-679. Recuperado de http://www.scielo.br/scielo.php?script=sci_ arttext\&pid=S1414-32832009000500017. doi: $10.1590 /$ S1414-32832009000500017

Gonçalves, C. V., Costa, J. S. D., Duarte G., Marcolin, A. C., Lima, L. C. V., Garlet G., ... Bianchi, M. S. (2009). Avaliação da frequência de realização do exame físico das mamas, da colpocitologia cervical e da ultrassonografia obstétrica durante a assistência pré-natal: uma inversão de valores. Revista da Associação Médica Brasileira, 55(3),290-295. Recuperado de http://www.scielo.br/scielo.php?script=sci_ abstract\&pid=S0104-42302009000300021\&lng=en\&nrm=i so\&tlng=pt. doi: $10.1590 / 50104-42302009000300021$

Guattari, F., \& Rolnik, S. (2005). Micropolítica: cartografias do desejo. Petrópolis, RJ: Vozes.

Henriques, R. P. (2012) A Medicalização da Existência e o Descentramento do Sujeito na Atualidade. Revista MalEstar e Subjetividade,12(3-4),793-816. Recuperado de http://pepsic.bvsalud.org/pdf/malestar/v12n3-4/13.pdf
Illich, I. (1975) A expropriação da saúde: nêmesis da Medicina. Rio de Janeiro: Nova Fronteira.

Johnson, R., \& Slade, P. (2002). Does fear of childbirth during pregnancypredict emergency caesarean section? BJOG: An International Journal of Obstetrics and Gynaecology, 109(11), 1213-21. Recuperado de https://www.ncbi. nlm.nih.gov/pubmed/12452457. doi: 10.1046/j.14710528.2002.01351.x

Jonsson, E., Banta, H. D., \& Schersten, T. (2001). Health technology assessment and screening in Sweden. Int J Technol Assess Health Care, 17(3), 380-388. Recuperado de https://www. ncbi.nlm.nih.gov/pubmed/11495381. doi: $10.1017 /$ s0266462301106094

Karhawi, I. (2015, outubro). Espetacularização do Eu e \#selfies: um ensaio sobre visibilidade midiática. Anais do Congresso Internacional em Comunicação e Consumo (Comunicon), São Paulo, SP, Brasil. Recuperado de http://anaiscomunicon2015.espm.br/GTs/GT6/18_GT06_KARHAWI.pdf

Lapa, T. S. (2008) Por que ser contra o Estatuto do Nascituro. Jornal Brasil de Fato, São Paulo, 4 jun. Recuperado de https://www.brasildefato.com.br/node/13114/

Lei n. 1.108, de 7 de abril de 2005. Altera a Lei 8.080, introduzindo o direito ao acompanhante de escolha durante o trabalho de parto, no parto e no pós-parto imediato. Recuperado de http://www.planalto.gov.br/ccivil_03/_Ato20042006/2005/Lei/L11108.htm

Mónico, L., Alferes, V., Parreira, P., \& Castro, P. A. (2017). A Observação Participante Enquanto metodologia de investigação qualitativa. Congresso Ibero-Americano em Investigação Qualitativa, Salamanca, Espanha, 3. Recuperado de https://www.researchgate.net/ publication/318702823_A_Observacao_Participante_ enquanto_metodologia_de_investigacao_qualitativa

Nakano, A. R, Bonan, C., \& Teixeira, L. A.(2015). A normalização da cesárea como modo de nascer: cultura material do parto em maternidades privadas no Sudeste do Brasil. Physis: Revista de Saúde Coletiva, 25(3), 885- 904. Recuperado de http://www.scielo.br/scielo.php?pid=S0103$73312015000300885 \&$ script=sci_abstract\&tlng=pt. doi: 10.1590/S0103-73312015000300011

Oliveira, R. A. C. M. (2017). Parto, Mercado e Violência - Uma análise discursiva. Revista Tropos, 6(1). Recuperado de https://periodicos.ufac.br/index.php/tropos/article/ view/1226

Orlandi, E. P. (2001). Análise do discurso: princípios e procedimentos (3a ed.) Campinas: Pontes. 
Orlandi, E. (2007). As Formas do Silêncio: no movimento dos sentidos (6a ed.). Campinas - SP: Unicamp.

Ortega, F. (2008). O corpo incerto: corporeidade, tecnologias médicas e cultura contemporânea. Cad. Saúde Pública, 26(2), 419-423. Recuperado de http://www.scielo.br/scielo. php?script=sci_arttext\&pid=S0102-311X2010000200021. doi: 10.1590/S0102-311X2010000200021

Ortega, F., \& Zorzanelli, R. (2010). O corpo em evidência: a ciência e a redefinição do humano. Trab. Educ. Saúde, 10(3),561-565. Recuperado de http://www.scielo.br/scielo. php?script=sci_arttext\&pid=S1981-77462012000300014. doi: 10.1590/S1981-77462012000300014

Pêcheux, M. (1995). Semântica e Discurso: uma crítica à afirmação do óbvio. Campinas: UNICAMP.

Rago, M., Orlandi, L. B. L., \& Veiga-Neto, A. (2002). Imagens de Foucault e Deleuze: ressonâncias nietzschianas. Rio de Janeiro: DP\&A.

Reading, A. E., Campbell S., Cox D.N., \& Sledmere C.M. (1982). Health beliefs and health care behaviour in pregnancy. Psychological Medicine, 12(2), 379-383. Recuperado de https://www.ncbi.nlm.nih.gov/pubmed/7100360. doi: 10.1017/s0033291700046717

Rezende, C. B. (2017). Histórias de parto e a ultrassonografia como marco narrativo no Rio de Janeiro. Sexualidad, Salud y Sociedad, 27,7-24. Recuperado de http://www.scielo.br/ pdf/sess/n27/1984-6487-sess-27-7.pdf. doi: 10.1590/19846487.sess.2017.27.02.a

Rodrigues, J. C. T., Almeida, I. E. S. R., Oliveira Neto, A. G., \& Moreira, T. A. (2016). Cesariana no Brasil: uma análise epidemiológica. Revista Multitexto, 4(1), 48-53. Recuperado de http://www.ead.unimontes.br/multitexto/index.php/ rmcead/article/view/174

Rolnik, S. (2003). "Fale com ele" ou como tratar o corpo vibrátil em coma. Recuperado de https://www.pucsp.br/ nucleodesubjetividade/Textos/SUELY/falecomele.pdf
Santos Neto, E.T., Alves, K. C. G., Zorzal, M., \& Lima, R. C. D. (2008). Políticas de saúde materna no Brasil: os nexos com indicadores de saúde materno-infantil. Saúde e Sociedade, 17(2), 107-119. Recuperado de http://www.scielo.br/ scielo.php?pid=S0104-12902008000200011\&script=sci_ abstract\&tIng=pt. doi: 10.1590/S0104-12902008000200011

World Health Organization (2002). WHO antenatal care randomized trial: manual for the implementation of the new model. World Health Organization. 